\title{
A Novel Multi-Ionophore Approach for Potentiometric Analysis of Lanthanide Mixtures
}

\author{
Julia Ashina 1,*, Vasily Babain ${ }^{1,2}$, Dmitry Kirsanov ${ }^{1,2}\left(\mathbb{D}\right.$ and Andrey Legin ${ }^{1,2, *}$ \\ 1 Institute of Chemistry, Mendeleev Center, St. Petersburg State University, Universitetskaya nab. 7/9, \\ 199034 St. Petersburg, Russia; v.babain@spbu.ru (V.B.); d.kirsanov@spbu.ru (D.K.) \\ 2 Laboratory of Artificial Sensory Systems, ITMO University, Kronverkskiy pr, 49, 197101 St. Petersburg, Russia \\ * Correspondence: y.ashina@spbu.ru (J.A.); a.legin@spbu.ru (A.L.)
}

check for

updates

Citation: Ashina, J.; Babain, V.; Kirsanov, D.; Legin, A. A Novel Multi-Ionophore Approach for Potentiometric Analysis of Lanthanide Mixtures. Chemosensors 2021, 9, 23. https://doi.org/ $10.3390 /$ chemosensors 9020023

Academic Editor: Núria Serrano Received: 7 December 2020

Accepted: 25 January 2021

Published: 27 January 2021

Publisher's Note: MDPI stays neutral with regard to jurisdictional claims in published maps and institutional affiliations.

Copyright: (c) 2021 by the authors. Licensee MDPI, Basel, Switzerland. This article is an open access article distributed under the terms and conditions of the Creative Commons Attribution (CC BY) license (https:// creativecommons.org/licenses/by/ $4.0 /)$.

\begin{abstract}
This work aims to discuss quantification of rare earth metals in a complex mixture using the novel multi-ionophore approach based on potentiometric sensor arrays. Three compounds previously tested as extracting agents in reprocessing of spent nuclear fuel were applied as ionophores in polyvinyl chloride (PVC)-plasticized membranes of potentiometric sensors. Seven types of sensors containing these ionophores were prepared and assembled into a sensor array. The multi-ionophore array performance was evaluated in the analysis of $\mathrm{Ln}^{3+}$ mixtures and compared to that of conventional monoionophore sensors. It was demonstrated that a multi-ionophore array can yield RMSEP (root mean-squared error of prediction) values not exceeding $0.15 \log C$ for quantification of individual lanthanides in binary mixtures in a concentration range 5 to $3 \mathrm{pLn}^{3+}$.
\end{abstract}

Keywords: potentiometric sensors; lanthanides; multisensory systems; sensor arrays

\section{Introduction}

Quantitative analysis of rare earth element (REE) mixtures is a challenging analytical task due to the significant similarity of the chemical properties of lanthanides. The toxicity of $\mathrm{Ln}^{3+}$ in ionic form is primarily associated with oxidative stress. $\mathrm{Ln}^{3+}$ detection in complex media is a part of REE ore mining and spent nuclear fuel (SNF) reprocessing to estimate the accompanying REE-induced biological and environmental effects. As REEassociated toxicity is confined mainly to $\mathrm{Ce}$, La and $\mathrm{Gd}$, the separate quantification of lanthanides, and estimating the accompanying REE-induced biological and environmental effects, are problems of utmost importance. This task is typically handled with heavy analytical instruments such as, e.g., inductively coupled plasma mass spectrometry (ICPMS). Alongside low detection limits, high accuracy and reproducibility of the method requires expensive equipment and is not suitable for operating in an on-line mode.

One of potential alternatives to sophisticated analytical instruments is potentiometric sensor analysis. Indeed, ion-selective electrodes (ISEs) with polymeric plasticized membranes are irreplaceable in analyzing ionic species in aqueous solutions. The working principle of ISEs is based on the complexation of the target analyte by a sensitive ligand (ionophore) that is immobilized in a lipophilic membrane matrix. Currently, plasticized PVC is the most popular type of membrane matrix for ion-selective electrodes, and there are many developed ionophores and membrane compositions involved in environmental monitoring [1] evaluation of food and beverage quality etc. [2]. Besides, sensors with polymeric membranes have proved efficient for technological control of PUREX (plutonium-uranium extraction) process in general [3] and, particularly, for monitoring of REE content in the reprocessing media [4-6].

Specific analytical tasks may require the design of a particular ionophore, which is a laborious and time-consuming procedure. Despite the abundance of existing ionophores, ISEs sometimes do not provide comprehensive information about the composition of 
complex objects due to the lack of selectivity most ionophores possess. For example, the determination of $\mathrm{Ln}^{3+}$ cations in their mixtures is hindered by their strong mutual interference, which requires an alternative approach for modifying sensor sensitivity patterns.

One of the obvious ways to avoid the procedure of ionophore design from scratch is the usage of chelating substances that have proven efficient in related fields, such as solvent extraction. Solvent extraction is based on the binding of metal cations by the extracting agent dissolved in the organic phase. The efficiency of the ion extraction process is determined by the distribution coefficient value $D_{c}$, which is a ratio of the total analytical concentration of a solute in the organic phase $\left(\mathrm{C}_{\mathrm{org}}\right)$ to its total analytical concentration in the aqueous phase $\left(\mathrm{C}_{\mathrm{aq}}\right)$.

Thus, the $\mathrm{D}_{\mathrm{c}}$ value is in direct proportion to the ligand-ion complex concentration in the organic (solvent) phase. Since both distribution coefficients and ISE selectivity depend heavily on the stability of the ligand-ion complex $[7,8]$, the $D_{c}$ values for a particular ligand can be used as a rough estimate of the sensor sensitivity. This has been confirmed with a number of extracting agents, such as bidentate phosphorus compounds, diamides and other heterocyclic ligands that were adopted from spent nuclear fuel reprocessing procedures and continue to be used as ionophores for polymeric plasticized ISEs [9-15].

Apart from currently implemented single-component solvent extraction systems, those containing a combination of several extracting agents were introduced in the 1980s, and the corresponding synergetic effects on extraction efficiency upon mixing different extracting agents were studied. For instance, the efficiency of the lanthanide extraction observed after adding picrolonic acid to the neutral bidentate extractant tetraphenylmethylenediphosphine dioxide (TPhMDPDO) was 10 to 100 times higher compared to using TPhMDPDO alone [16].

The significant number of such synergistic systems in solvent extraction led us to the idea that mixing several ionophores within one potentiometric sensor membrane may result in similar benefits. It was assumed that such multi-ionophore sensors may have sensitivity patterns different from those of classical monoionophore sensors. However, one cannot anticipate the particular synergistic effects for the given combination of ligands in the extraction procedures. One representative example is the combination of octyl(phenyl)-N,N-diisobutyl-carbamoylmethyl-phosphine oxide (CMPO) and bis-(2ethylhexyl)phosphoric acid (HDEHP). Despite the fact that these ligands demonstrated beneficial synergistic effects in single-step TRUSPEAK extraction process [17], the excess of HDEHP over CMPO results in a decrease in the distribution ratio of $\mathrm{Eu}^{3+}$ extraction [18].

It was shown that the selectivity of chelate formation, and thus the stability of the $\mathrm{Ln}^{3+}-\mathrm{L}$ complex for the heterocyclic ligands and lanthanide cations, can be predicted with the Density Functional Theory methods optimized for the gas phase [19]. However, the influence of the polymeric sensor membrane matrix on the $\mathrm{Ln}^{3+}-\mathrm{L}$ complex formation and the potentiometric selectivity of lanthanides determination is not likely to be predicted by theoretical methods, especially for membranes containing several ionophores. For this reason, synergistic effects on the corresponding multi-ionophore sensor performance were assessed empirically upon lanthanide mixture analysis, and the ligands were chosen out of diversity in the sensitivity patterns and the $\mathrm{Ln}^{3+}$ extraction efficiency.

The idea of using several ionophores in one sensor membrane was implemented earlier for the miniaturization of an ion chromatography detector [20], in voltametric sensors [21-23], a pseudo reference potentiometric sensor [24] and to investigate the stability constants of ion-carrier complexes [25]. This approach has never been reported for zerocurrent potentiometry until now. This work is aimed at validating the multi-ionophore sensing concept in ion mixtures analysis.

The three ligands in this study were chosen with regards to the sensitivity patterns of the corresponding sensors in the $\mathrm{Ln}^{3+}$ analysis. The first ionophore, diphenyl-N,N-din-butylcarbamoylmethylphoshine oxide (DPCMPO) [26], exhibits higher complexation ability towards light lanthanides than to heavy ones [27], so DPCMPO-based sensors would have a descending sensitivity pattern. The sensitivity pattern provided by the 
second ligand, $\mathrm{N}, \mathrm{N}, \mathrm{N}^{\prime}, \mathrm{N}^{\prime}$-tetra(n-octyl)diglycolamide (TODGA) is an ascending curve, because TODGA-based sensors show higher sensitivity to the heavy lanthanides rather than to the light ones. The third extracting agent, $\mathrm{N}_{1} \mathrm{~N}^{\prime}$-diethyl- $\mathrm{N}, \mathrm{N}^{\prime}$-di(p)-fluorophenyl dipicolinamide (DPA), is supposed to provide for moderate sensor sensitivity values to all lanthanides [28]. The sensitivity values and selectivity coefficients of multi-ionophore sensors were determined and compared to those of traditional single-ionophore ISEs in order to estimate the effectiveness of the multi-ionophore approach.

Achieving selective multianalyte detection by a multistep analysis with different potentiometric sensors is unlikely one by one. For this reason, an array of cross-sensitive multi-ionophore sensors was used in order to compensate for the insufficient selectivity in the $\mathrm{Ln}^{3+}$ determination. Apart from the time efficiency of the technique, multisensory approach combined with multivariate data processing methods (see e.g., [29]) may allow for the quantification of individual components in complex mixtures. In this work, the multiionophore sensor array performance in determination of individual $\mathrm{Ln}^{3+}$ concentrations was tested in the analysis of binary solutions. For this purpose, the sensor readings acquired simultaneously from the whole array, and the resulting multivariate data, were processed using a Partial Least Squares (PLS) algorithm [30]. PLS is a commonly used technique in multivariate data analysis, including electronic tongue data treatment [31].

\section{Materials and Methods}

\subsection{Reagents}

High-molecular weight PVC, o-nitrophenyloctyl ether (NPOE) and potassium tetrakis [3,5-bis(trifluormethyl)phenyl] borate (KTTFPB) were obtained from Fluka Chemical (Buchs, Switzerland). Diphenyl-N,N-di-n-butylcarbamoylmethylphoshine oxide (DPCMPO) was synthesized and purified at the Institute of Chemical Reagents and Special-Purity Chemical Substances (IREA, Moscow, Russia). $\mathrm{N}, \mathrm{N}, \mathrm{N}^{\prime}, \mathrm{N}^{\prime}$-tetra(n-octyl)diglycolamide (TODGA) was kindly provided by Dr. B. Casensky (Katchem, Prague, Czech Republic). $\mathrm{N}, \mathrm{N}^{\prime}$-diethyl-N, $\mathrm{N}^{\prime}$-di(p)-fluorophenyl dipicolinamide (DPA), was contributed by the Khlopin Radium Institute (St. Petersburg, Russia).

Lanthanide nitrates for the calibrations were used as $1 \mathrm{M}$ stock solutions in $10^{-2} \mathrm{M} \mathrm{HNO}_{3}$.

\subsection{Membrane Compositions}

The sensor array consisted of 21 sensors: seven membrane compositions and three of each type. The membrane matrix consisted of PVC (33.5 wt. \%) and plasticizer NPOE (66.5 wt. \%). All membranes contained $10 \mathrm{mmol} / \mathrm{kg}$ of lipophilic additive KTTFPB and $50 \mathrm{mmol} / \mathrm{kg}$ of ionophore(s) in total. The membranes M1-M3 contained $50 \mathrm{mmol} / \mathrm{kg}$ of single ionophores DPCMPO, TODGA and DPA, respectively. The membranes M5-M7 contained binary mixtures of ionophores with $25 \mathrm{mmol} / \mathrm{kg}$ each. The membrane $\mathrm{M} 4$ simultaneously contained three ionophores of $16.67 \mathrm{mmol} / \mathrm{kg}$ each. All studied compositions are listed in Table 1.

Table 1. Membrane compositions (in $\mathrm{mg}$ ).

\begin{tabular}{ccccccc}
\hline \multirow{2}{*}{$\#$} & \multicolumn{3}{c}{$\mathbf{m}_{\text {ionophore, }} \mathbf{m g}$} & $\mathbf{m}_{\text {plasticizer }}$ & $\mathbf{m}_{\mathbf{P V C}}$ & $\begin{array}{c}\mathbf{m}_{\text {lipophilic }} \\
\text { additive }\end{array}$ \\
\cline { 2 - 5 } & DPCMPO & TODGA & DPA & & & 1.5 \\
M1 & 5.6 & - & - & 194.5 & 97.2 & 1.5 \\
M2 & - & 8.7 & - & 192.4 & 96.2 & 1.5 \\
M3 & - & - & 6.1 & 194.1 & 97.1 & 1.5 \\
M4 & 1.8 & 2.9 & 2.0 & 193.7 & 96.8 & 1.5 \\
M5 & 2.8 & 4.4 & - & 193.4 & 96.7 & 1.5 \\
M6 & 2.8 & - & 3.1 & 194.3 & 97.1 & 1.5 \\
M7 & - & 4.4 & 3.1 & 193.2 & 96.6 &
\end{tabular}

The sensor membranes were prepared according to standard procedure. All the weighed components were dissolved in freshly distilled tetrahydrofuran (THF) by stirring. 
After the complete dissolution of the components, the membrane cocktails were poured into $3 \mathrm{~mL}$ Teflon cylindrical vessels and left for $48 \mathrm{~h}$ until the THF was completely evaporated. 8-mm diameter circles of the membranes (three per composition) were cut and glued onto the sensor body using the mixture of PVC and cyclohexanone. All sensors were conditioned at $0.01 \mathrm{M} \mathrm{NaCl}$ prior to the measurements.

The visual appearance of the sensor array with the reference electrode is given in the Figure S1 (Supplementary Materials).

\subsection{Potentiometric Measurements}

Potentiometric measurements were performed using digital mV-meter HAN-11 (Sensor Systems LLC, St. Petersburg, Russia) against the standard Ag/AgCl reference electrode (Izmeritelnaya Tekhnika, Moscow, Russia) in the following galvanic cell:

$\mathrm{Ag}|\mathrm{AgCl}| \mathrm{KCl}_{\text {sat }} \mid$ | sample solution | sensor membrane | $\mathrm{NaCl}, 0.01 \mathrm{M}|\mathrm{AgCl}| \mathrm{Ag}$.

A standard glass $\mathrm{pH}$ electrode (Izmeritelnaya Tekhnika, Moscow, Russia) was used for $\mathrm{pH}$ control during measurements.

The electromotive force (EMF) of the described electrochemical cell was registered for each of the M1-M7 sensors in $10^{-7}-10^{-3} \mathrm{M}$ aqueous solutions of the corresponding lanthanide nitrates in nitric acid $(\mathrm{pH}=2)$. The time of measurements was three minutes and was sufficient time for reaching the equilibrium at the sample/membrane interface.

The sensor sensitivity was expressed as a slope of the linear part of the response function according to the Nernst equation. The sensitivity for each type of the sensor was calculated as the mean value of three replica sensors of the same composition and three repeated measurements. The standard deviation of sensitivity values did not exceed $1 \mathrm{mV} /$ dec.

The selectivity characteristics of the sensors were evaluated using the fixed interference method [32]. The selectivity coefficients $K_{\mathrm{Ln}} / \mathrm{La}$ were calculated from the calibrations in $10^{-7}-10^{-3} \mathrm{M} \mathrm{Ln}^{3+}$ solutions with a background of $10^{-5} \mathrm{M} \mathrm{La}^{3+}$.

The distribution ratio, $D_{c}$ is the main parameter of the extraction efficiency. Since the $D_{c}$ values are often in agreement to the selectivity series of the corresponding ligand-based ISE [11], the $\mathrm{D}_{\mathrm{c}}$ data reported in the literature was used for the multi-ionophore sensor selectivity data interpretation.

To investigate the ability of the proposed array to distinguish the lanthanide cations in mixtures, a set of $35 \mathrm{La}^{3+}-\mathrm{Nd}^{3+}$ solutions was analyzed. The experimental design (see Table S1, Supplementary Materials) was performed according to the procedure in [33]. In order to demonstrate how the multivariate sensor response can be used for the estimation of $\mathrm{Ln}^{3+}$ concentration in mixtures, the sensor array data (shown in Table S2, Supplementary Materials) was processed using the PLS regression algorithm. The main parameter to estimate PLS model quality is the root mean square error of prediction (RMSEP). RMSEP in this case has concentration units and can be calculated using the following equation:

$$
\text { RMSEP }=\sqrt{\frac{\sum_{i=1}^{n}\left(C_{i, \text { pred }}-C_{i, \text { ref }}\right)^{2}}{n}}
$$

where $C_{i}$,pred $-C$ value is predicted with a model, $C_{i, r e f}-$ reference y value (known concentration of the analyte), $\mathrm{n}$-the number of samples in the selected test set.

Another PLS model quality criterion is the squared correlation coefficient $\mathrm{R}^{2}$, describing the deviation of the predicted $C_{i \text {,pred }}$ from the reference concentration values $\mathrm{C}_{\mathrm{i} \text {,ref }}\left(\mathrm{R}^{2}=1\right.$ for the model that fits the data perfectly). The 25-point subset from 35-point dataset was used for the calibration and the 10-point subset was used to validate the resulting model.

Multivariate data analysis was performed in Unscrambler 9.7 (CAMO, Oslo, Norway) software. 


\section{Results and Discussion}

\subsection{Sensor Sensitivity}

In order to estimate the effect of several ionophores' incorporation into the membrane, the characteristics of conventional sensors with one ionophore (M1-M3) and multiple ionophores (M4-M7) were compared. For the first step, the sensitivities to lanthanide cations for all sensors were calculated. As an example, the calibration curves for sensors $\mathrm{M} 1, \mathrm{M} 3$ and $\mathrm{M} 6$ in $10^{-7}-10^{-3} \mathrm{M} \mathrm{Nd}^{3+}$ concentration range are presented in Figure 1.

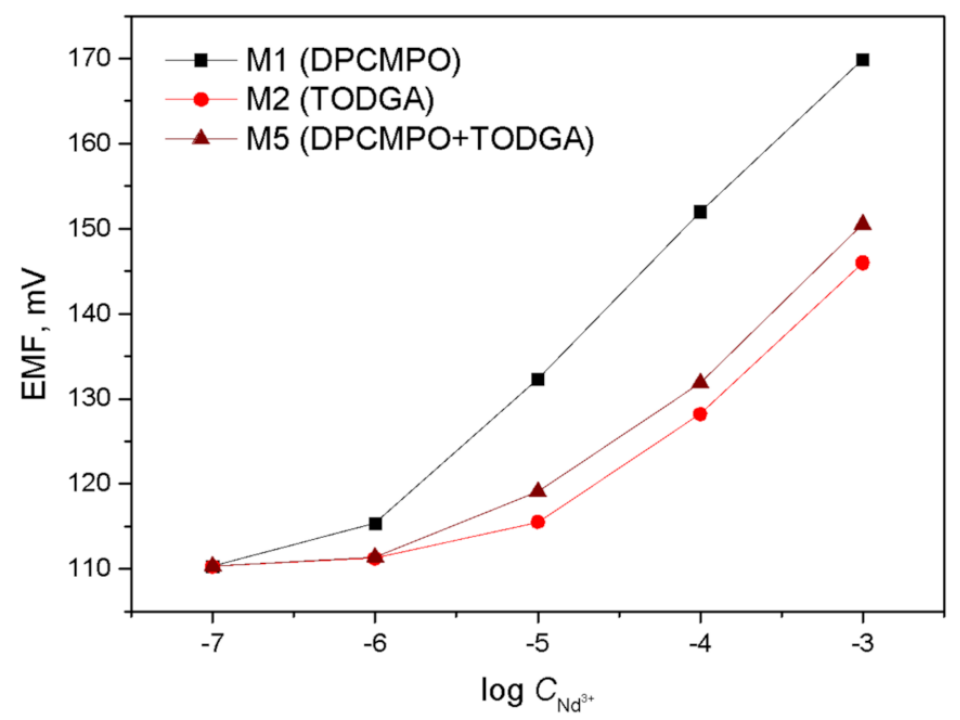

Figure 1. Typical calibration curves for sensors $\mathrm{M} 1, \mathrm{M} 3$ and $\mathrm{M} 6$ in $\mathrm{Nd}^{3+}$ solutions.

To estimate the sensor sensitivity, the linear part of the electrode function, as the response is described by the Nernst equation, was selected:

$$
\mathrm{E}=\mathrm{E}^{0}+\frac{\mathrm{RT}}{\mathrm{z}_{i} \mathrm{~F}} \ln a_{\left.\mathrm{i}_{(\mathrm{aq})}\right)^{\prime}}
$$

The sensitivities to $\mathrm{Ln}^{3+}$ for sensors M1-M7 are shown in Figures 2 and 3. We used the concentration values instead of the activities since activity coefficients are not available for the studied system: lanthanide nitrates in nitric acid.

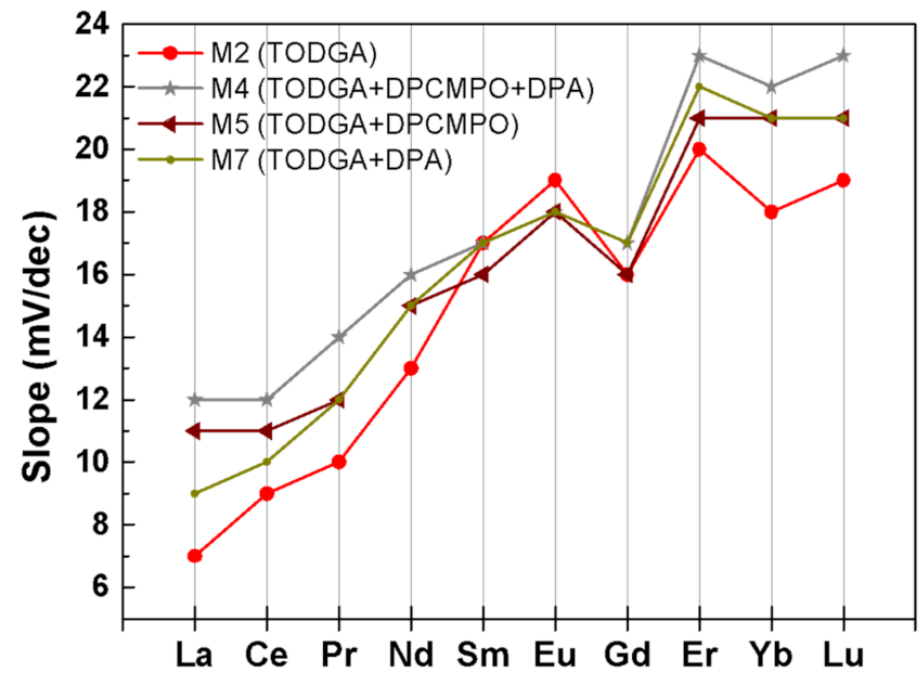

Figure 2. Sensor sensitivity patterns for $\mathrm{N}, \mathrm{N}, \mathrm{N}^{\prime}, \mathrm{N}^{\prime}$-tetra(n-octyl)diglycolamide (TODGA)-containing sensors, $\pm 1 \mathrm{mV} /$ dec. 


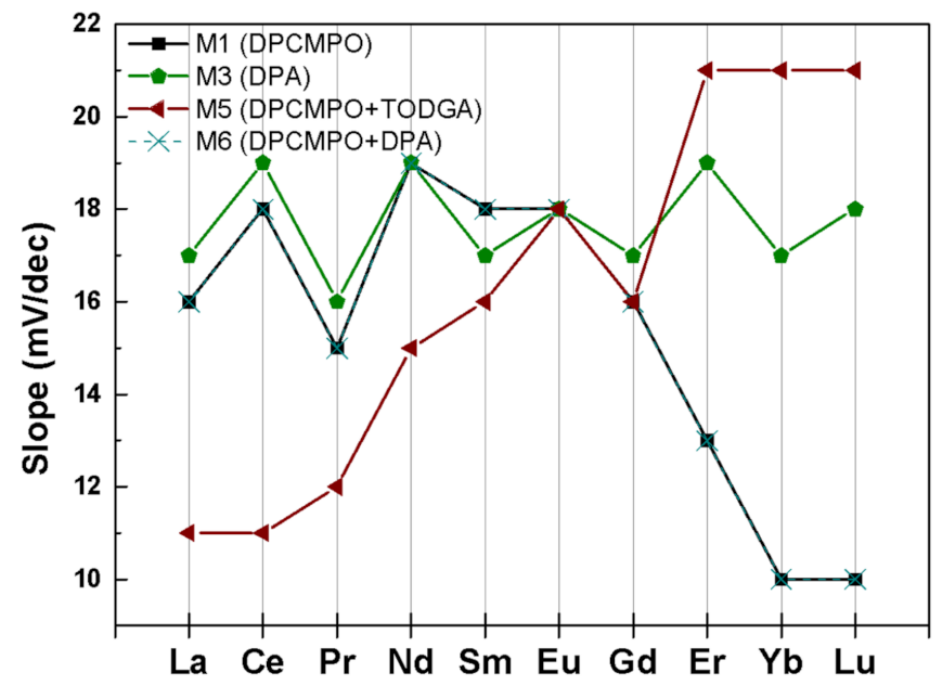

Figure 3. The sensitivity patterns for the sensors M1, M5, M6 diphenyl-N,N-di-nbutylcarbamoylmethylphoshine oxide (DPCMPO)-based membranes) and the N,N'-diethyl-N, $\mathrm{N}^{\prime}$ di(p)-fluorophenyl dipicolinamide (DPA)-based sensor $\mathrm{M} 3, \pm 1 \mathrm{mV} / \mathrm{dec}$.

The relative sensitivity values of the monoionophore sensors M1-M3 corresponded with the performance of the corresponding ligands as extracting agents. The DPCMPObased sensor M1 demonstrated higher sensitivity towards lighter lanthanides. The TODGAbased sensor M2 had higher sensitivity values towards heavy lanthanides. The DPA in sensors provided for moderate sensitivity about $16-19 \mathrm{mV} / \mathrm{dec}$ in the whole lanthanide range. All TODGA-containing sensors M4, M5, and M7, regardless of other ligands' presence, resembled the sensitivity pattern identical to that of the monoionophore TODGAbased sensor M2 (Figure 3). TODGA-based sensors had the highest sensitivity values towards heavy lanthanides among all sensors M1-M7.

In order to clarify the reasons for the particular sensitivity patterns of multi-ionophore sensors, the values of the distribution ratio for DPCMPO, TODGA and DPA within lanthanides extraction were assessed, as they are directly correlated with the stability constants of the ion-ligand complex. According to the literature, TODGA as an extracting agent is more effective with heavier lanthanides rather than the light ones [34], and the distribution ratio (D) is several orders higher than that of DPCMPO [35] and DPA [36] under similar experimental conditions. In general, $\mathrm{D}_{\mathrm{Ln}}{ }^{3+}$ values decrease in the TODGA $>>$ DPCMPO $>$ DPA series. This explains the prevalence of the TODGA sensitivity pattern over the sensitivity patterns of DPCMPO and DPA.

The sensitivity values of all DPCMPO-based sensors M1, M5, and M6 decrease with the atomic number of the lanthanide (Figure 3) as well as the $\mathrm{D}_{\mathrm{Ln}}{ }^{3+}$ distribution ratio values for extraction with carbamoyl phosphine oxides [26,27].

Sensor M6, which contains both DPCMPO and DPA, tended to have the DPCMPO sensitivity pattern. The average $\mathrm{D}_{\mathrm{Ln}}{ }^{3+}(\mathrm{DPCMPO})>\mathrm{D}_{\mathrm{Ln}}{ }^{3+}(\mathrm{DPA}), \mathrm{DPCMPO}$ had higher complexation ability than DPA, thus providing for the DPCMPO sensitivity pattern in DPCMPO-DPA sensor M6. As a result, the DPA-sensitivity pattern could only be observed in the monoionophore DPA-based M3 membrane without the other two ligands added.

\subsection{Selectivity of $\mathrm{Ln}^{3+}$ Determination}

To assess the mutual interference of lanthanide cations in their mixtures, the sensor selectivity parameter was chosen. The EMF values in lanthanide solutions were registered in the presence of $10^{-5} \mathrm{M} \mathrm{La}^{3+}$ and then the selectivity coefficients $K_{\mathrm{Ln} / \mathrm{La}}$ were calculated according to the fixed interference method protocol [32]. The results are shown in Table 2. 


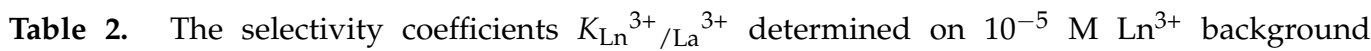
$\left( \pm 0.1 \mathrm{~K}_{\mathrm{Ln}}^{3+} / \mathrm{La}^{3+}\right)$.

\begin{tabular}{cccccccc}
\hline $\begin{array}{c}\text { Primary } \\
\mathbf{L n}^{3+} \text { ion/Sensor no. }\end{array}$ & M1 & M2 & M3 & M4 & M5 & M6 & M7 \\
\hline Ce & 0.4 & 3.2 & 0.4 & 0.8 & 1.6 & 0.4 & 0.4 \\
$\mathrm{Pr}$ & 0.8 & $>>10$ & 1.6 & $>>10$ & $>>10$ & 3.2 & 10.0 \\
$\mathrm{Nd}$ & 0.3 & 0.2 & 0.6 & 0.3 & 0.5 & 0.5 & 0.3 \\
$\mathrm{Sm}$ & 1.6 & 0.3 & 1.0 & 0.6 & 0.6 & 1.3 & 0.6 \\
$\mathrm{Eu}$ & 0.5 & 0.1 & 0.2 & 0.1 & 0.1 & 1.0 & 0.1 \\
$\mathrm{Gd}$ & 1.0 & 0.3 & 0.3 & 0.2 & 0.2 & 1.0 & 0.2 \\
$\mathrm{Er}$ & 3.9 & 0.4 & 1.0 & 0.4 & 0.2 & 5.0 & 0.1 \\
\hline
\end{tabular}

As expected, TODGA-based sensors (M4, M5, M7) demonstrated higher selectivity towards heavy lanthanides. For instance, the $\mathrm{Ln}_{\mathrm{Ln}}{ }^{3+} / \mathrm{La}^{3+}$ was $<1$ in the case of lanthanides heavier than $\mathrm{Nd}^{3+}$. DPCMPO-based sensors M1 and M6, with more pronounced light $\mathrm{Ln}^{3+}$

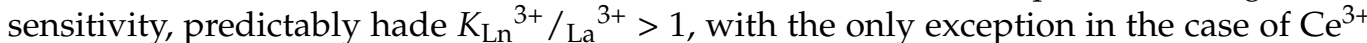
$\left(\mathrm{KCe}^{3+} / \mathrm{La}^{3+}<1\right)$. The DPA-based M3 sensor had a $\mathrm{KLn}^{3+} / \mathrm{La}^{3+}$ value of about 1 in most cases, which is, again, in agreement with the previously observed moderate sensitivity to the whole $\mathrm{Ln}^{3+}$ range.

Both light and heavy sensitive sensors demonstrated high sensitivity to neodymium in the presence of $\mathrm{Ln}^{3+}$. To assess the impact of the multi-ionophore multisensory system performance on the strong mutual interference of mixture components, a set of $\mathrm{La}^{3+}-\mathrm{Nd}^{3+}$ binary solutions was analyzed.

\subsection{Binary Mixtures Analysis}

In the next step of the study, the sensor array consisting of both mono and multiionophore sensors was used in the analysis of $\mathrm{La}^{3+}-\mathrm{Nd}^{3+}$ binary mixtures. In order to relate the multivariate sensor array response with the $\mathrm{Ln}^{3+}$ content, the data acquired from a set of $35 \mathrm{La}-\mathrm{Nd}$ solutions were analyzed using PLS regression. Additional PLS regression models were built based on the following subsets of the sensor array according to their sensitivity patterns: light Ln-sensitive (M1, M3, M6), and heavy Ln-sensitive (M2, M4, M5, M7). The $R^{2}$ and RMSEP parameters of the models were compared to those built for the complete array (M1-M7) (Table 3).

Table 3. Partial Least Squares (PLS) models based on complete sensor array data and partial data from sensor subsets for La-Nd binary mixtures analysis. RMSEP-Root Mean Square Error of Prediction, $\mathrm{R}^{2}$ —squared correlation coefficient, $\mathrm{N}$-number of PLS factors (latent variables).

\begin{tabular}{cccccccccc}
\hline & \multicolumn{3}{c}{$\mathbf{L a}^{3+}$} & \multicolumn{5}{c}{$\mathbf{N d}^{3+}$} \\
\cline { 2 - 9 } Sensor Set & Slope & $\begin{array}{c}\text { RMSEP } \\
(\mathbf{l o g})\end{array}$ & $\mathbf{R}^{2}$ & $\mathbf{N}$ & Slope & $\begin{array}{c}\text { RMSEP } \\
(\mathbf{l o g})\end{array}$ & $\mathbf{R}^{2}$ & $\mathbf{N}$ \\
\hline $\begin{array}{c}\text { Complete array } \\
\text { (M1-M7) }\end{array}$ & 0.69 & 0.12 & 0.85 & 4 & 1.14 & 0.15 & 0.89 & 2 \\
$\begin{array}{c}\text { light-sensitive } \\
\text { (M1 + M3 + M6) } \\
\text { heavy-sensitive }\end{array}$ & 0.84 & 0.09 & 0.90 & 3 & 0.31 & 0.35 & 0.40 & 3 \\
$(\mathrm{M} 2+$ M4 + M5 + M7) & 0.37 & 0.24 & 0.55 & 2 & 1.06 & 0.13 & 0.91 & 2 \\
\hline
\end{tabular}

The light-sensitive part of the array is best suited for the determination of the lighter $\mathrm{La}^{3+}$ as the PLS model gave the lowest RMSEP value (i.e., $0.09 \log C$ ) and the highest $\mathrm{R}^{2}=0.90$. The RMSEP obtained for the full array was relatively low as well $(0.12 \log C)$. This subarray was not suitable for Nd3+ quantification (RMSEP $=0.35 \log C$ and $R^{2}=0.4$ ).

As expected, the heavy-sensitive part did not show high precision of $\mathrm{La}^{3+}$ determination (RMSEP $=0.24 \log C$ ). This subset demonstrated better performance of the heavier 
$\mathrm{Nd}^{3+}$ concentration prediction (RMSEP $=0.13 \log \mathrm{C}, \mathrm{R}^{2}=0.91$ ), which was comparable to that of the full array (RMSEP $=0.15 \log C, R^{2}=0.89$ ).

Overall, the resulting PLS models based on the complete sensor array data demonstrated sufficient precision in predicting both $\mathrm{Nd}^{3+}$ and $\mathrm{La}^{3+}$ concentrations and the reliability of these models was confirmed by the relatively high $\mathrm{R}^{2}$ values. Nevertheless, the fact that the model for $\mathrm{La}^{3+}$ determination was based on four latent variables may be a sign of overfitting [37], and thus the light-sensitive part of the array (sensors M1, M3, M6) suits better for this task.

Overall, the significant influence of the TODGA ligand was observed for most of multi-ionophore sensor sensitivity patterns in this work. Therefore, further improvement of the proposed approach can be done using alternative ionophores. In future, the selection of ligands with comparable complexation ability (i.e., ion-ligand complex stability constant) should be done in order to perform the analysis of mixtures in a more flexible and effective way.

\section{Conclusions}

This study contributes to the monitoring development of a simple and cost-efficient analytical technology for quantification of the individual $\mathrm{Ln}^{3+}$ concentration in complex. The proposed approach consisted of the modification of potentiometric sensitivity patterns by mixing multiple ionophores in one polymeric sensor membrane. The set of the resulting multi-ionophore sensors demonstrated slight differences in the analytical parameters compared to those of conventional mono-ionophore sensors. The corresponding multiionophore sensor array showed reasonable precision in the analysis of binary $\mathrm{La}^{3+}$ and $\mathrm{Nd}^{3+}$ mixtures, which was sufficient for the needs of technological monitoring.

Supplementary Materials: The following are available online at https:/ / www.mdpi.com/2227-904 0/9/2/23/s1, Table S1: La-Nd mixtures composition, Table S2: Sensor array data. Figure S1: The visual appearance of the sensor array with a reference electrode.

Author Contributions: Conceptualization, D.K. and V.B.; methodology, formal analysis, and investigation, J.A.; resources, A.L. and V.B.; data curation, J.A. and D.K.; writing-original draft preparation, J.A.; writing-review and editing, D.K. and A.L.; supervision, D.K.; project administration A.L.; funding acquisition, J.A. All authors have read and agreed to the published version of the manuscript.

Funding: This research was funded by Russian Foundation of Basic Research (RFBR), grant № 18-33-01015.

Institutional Review Board Statement: Not applicable.

Informed Consent Statement: Not applicable.

Data Availability Statement: Not applicable.

Conflicts of Interest: The authors declare no conflict of interest.

\section{References}

1. Crespo, G.A. Recent Advances in Ion-selective membrane electrodes for in situ environmental water analysis. Electrochim. Acta 2017, 245, 1023-1034. [CrossRef]

2. Gallardo, J.; Alegret, S.; Del Valle, M. Application of a potentiometric electronic tongue as a classification tool in food analysis. Talanta 2005, 66, 1303-1309. [CrossRef] [PubMed]

3. Oleneva, E.; Savosina, J.; Agafonova-Moroz, M.; Lumpov, A.; Babain, V.; Jahatspanian, I.; Legin, A.; Kirsanov, D. Potentiometric multisensor system for tetra- and hexavalent actinide quantification in complex rare earth metal mixtures related to spent nuclear fuel reprocessing. Sens. Actuators B Chem. 2019, 288, 155-162. [CrossRef]

4. Chen, Q.; Ma, X.; Zhang, X.; Liu, Y.; Yu, M. Extraction of rare earth ions from phosphate leach solution using emulsion liquid membrane in concentrated nitric acid medium. J. Rare Earths 2018, 36, 1190-1197. [CrossRef]

5. He, J.; Li, Y.; Xue, X.; Ru, H.; Huang, X.; Yang, H. A novel Ce(IV) ion-selective polyvinyl chloride membrane electrode based on HDEHP and HEH/EHP. J. Rare Earths 2017, 35, 934-940. [CrossRef]

6. Kirsanov, D.; Khaydukova, M.; Tkachenko, L.; Legin, A.; Babain, V. Potentiometric Sensor Array for Analysis of Complex Rare Earth Mixtures. Electroanalysis 2012, 24, 121-130. [CrossRef] 
7. Hoh, Y.C.; Nevarez, M.; Bautista, R.G. A Predictive Thermodynamic Model for the Distribution Coefficients of Neodymium in the Nd(NO3)3-HNO3-H2O-1 M HDEHP-Amsco Liquid-Liquid Extraction System. Ind. Eng. Chem. Process Des. Dev. 1978, 17, 88-91. [CrossRef]

8. Bakker, E.; Simon, W. Selectivity of ion-sensitive bulk optodes. Anal. Chem. 1992, 64, 1805-1812. [CrossRef]

9. Alyapyshev, M.; Babain, V.; Borisova, N.; Eliseev, I.; Kirsanov, D.; Kostin, A.; Legin, A.; Reshetova, M.; Smirnova, Z. 2,2'-Dipyridyl6,6'-dicarboxylic acid diamides: Synthesis, complexation and extraction properties. Polyhedron 2010, 29, 1998-2005. [CrossRef]

10. Alyapyshev, M.Y.; Babain, V.A.; Boyko, V.I.; Eliseev, I.I.; Kirsanov, D.O.; Klimchuk, O.V.; Legin, A.V.; Mikhailina, E.S.; Rodik, R.V.; Smirnov, I.V. Calixarenes functionalized with phosphine oxide and diamide functions as extractants and ionofores for rare-earth metals. J. Incl. Phenom. Macrocycl. Chem. 2010, 67, 117-126. [CrossRef]

11. Legin, A.V.; Babain, V.A.; Kirsanov, D.O.; Mednova, O.V. Cross-sensitive rare earth metal ion sensors based on extraction systems. Sens. Actuators B Chem. 2008, 131, 29-36. [CrossRef]

12. Khaydukova, M.; Militsyn, D.; Karnaukh, M.; Grüner, B.; Selucký, P.; Babain, V.; Wilden, A.; Kirsanov, D.; Legin, A. Modified Diamide and Phosphine Oxide Extracting Compounds as Membrane Components for Cross-Sensitive Chemical Sensors. Chemosensors 2019, 7, 41. [CrossRef]

13. Babain, V.A.; Legin, A.V.; Kirsanov, D.O.; Rudnitskaya, A.M.; Tatuev, Y.M.; Baulin, V.E. New chemical sensors based on extraction systems for stable fission products analysis. Radiochim. Acta 2009, 97, 479-484. [CrossRef]

14. Kirsanov, D.O.; Borisova, N.E.; Reshetova, M.D.; Ivanov, A.V.; Korotkov, L.A.; Eliseev, I.I.; Alyapyshev, M.Y.; Spiridonov, I.G.; Legin, A.V.; Vlasov, Y.G.; et al. Novel diamides of 2,2'-dipyridyl-6,6'-dicarboxylic acid: Synthesis, coordination properties, and possibilities of use in electrochemical sensors and liquid extraction. Russ. Chem. Bull. 2013, 61, 881-890. [CrossRef]

15. Kirsanov, D.O.; Legin, A.V.; Babain, V.A.; Vlasov, Y.G. Polymeric sensors based on extraction systems for determination of rare-earth metals. Russ. J. Appl. Chem. 2005, 78, 568-573. [CrossRef]

16. Turanov, A.N.; Karandashev, V.K. Synergistic Solvent Extraction of Lanthanides (III) with Mixtures of Tetraphenylmethylenediphosphine Dioxide and Picrolonic Acid from HCl Solutions. Solvent Extr. Ion Exch. 2017, 35, 104-116. [CrossRef]

17. Lumetta, G.J.; Carter, J.C.; Gelis, A.V.; Vandegrift, G.F. Combining Octyl(phenyl)-N,N-diisobutylcarbamoylmethylphosphine oxide and bis-(2-ethylhexyl)phosphoric acid extractants for recovering transuranic elements from irradiated nuclear fuel. In ACS Symposium Series; American Chemical Society: Washington, DC, USA, 2010; Volume 1046, pp. 107-118.

18. Tkac, P.; Vandegrift, G.F.; Lumetta, G.J.; Gelis, A.V. Study of the Interaction between HDEHP and CMPO and Its Effect on the Extraction of Selected Lanthanides. Ind. Eng. Chem. Res. 2012, 51, 10433-10444. [CrossRef]

19. Borisova, N.E.; Eroshkina, E.A.; Korotkov, L.A.; Ustynyuk, Y.A.; Alyapyshev, M.Y.; Eliseev, I.I.; Babain, V.A. Actinide-Lanthanide Separation by Bipyridyl-Based Ligands: DFT Calculations and Experimental Results. In Proceedings of the 10th International Conference Toward and over the Fukushima Daiichi accident, Chiba, Japan, 11-16 December 2011.

20. Hyun Han, S.; Shin Lee, K.; Sig Cha, G.; Liu, D.; Trojanowicz, M. Potentiometric detection in ion chromatography using multi-ionophore membrane electrodes. J. Chromatogr. A 1993, 648, 283-288. [CrossRef]

21. Cuartero, M.; Crespo, G.A.; Bakker, E. Ionophore-Based Voltammetric Ion Activity Sensing with Thin Layer Membranes. Anal. Chem. 2016, 88, 1654-1660. [CrossRef]

22. Jadhav, S.; Bakker, E. Selectivity Behavior and Multianalyte Detection Capability of Voltammetric Ionophore-Based Plasticized Polymeric Membrane Sensors. Anal. Chem. 2001, 73, 80-90. [CrossRef]

23. Crespo, G.A.; Cuartero, M.; Bakker, E. Thin Layer Ionophore-Based Membrane for Multianalyte Ion Activity Detection. Anal. Chem. 2015, 87, 7729-7737. [CrossRef] [PubMed]

24. Murphy, L.; Slater, J.M. Multi-Ionophore Membrane Electrode. U.S. Patent No. DE60311517T2, 28 November 2002.

25. Bakker, E.; Pretsch, E. Ion-Selective Electrodes Based on Two Competitive Ionophores for Determining Effective Stability Constants of Ion-Carrier Complexes in Solvent Polymeric Membranes. Anal. Chem 1998, 70, 295-302. [CrossRef]

26. Legin, A.V.; Kirsanov, D.O.; Babain, V.A.; Borovoy, A.V.; Herbst, R.S. Cross-sensitive rare-earth metal sensors based on bidentate neutral organophosphorus compounds and chlorinated cobalt dicarbollide. Anal. Chim. Acta 2006, 572, $243-247$. [CrossRef] [PubMed]

27. Horwltz, E.P.; Martin, K.A.; Diamond, H.; Kaplan, L. Extraction of Am from Nitric Acid by Carbamoyl-Phosphoryl Extractants: The Influence of Substituents on The Selectivity of Am Over Fe and Selected Fission Products. Solvent Extr. Ion Exch. 1986, 4, 449-494. [CrossRef]

28. Babain, V.A.; Alyapyshev, M.Y.; Kiseleva, R.N. Metal extraction by N,N'-dialkyl-N,N'-diaryl-dipicolinamides from nitric acid solutions. Radiochim. Acta 2007, 95, 217-223. [CrossRef]

29. Richards, E.; Bessant, C.; Saini, S. Multivariate data analysis in electroanalytical chemistry. Electroanalysis 2002, 14, 1533-1542. [CrossRef]

30. Wold, S.; Sjöström, M.; Eriksson, L. PLS-regression: A basic tool of chemometrics. Chemom. Intell. Lab. Syst. 2001, 58, 109-130. [CrossRef]

31. Ciosek, P.; Mamińska, R.; Dybko, A.; Wróblewski, W. Potentiometric electronic tongue based on integrated array of microelectrodes. Sens. Actuators B Chem. 2007, 127, 8-14. [CrossRef]

32. Bakker, E.; Pretsch, E.; Bühlmann, P. Selectivity of potentiometric ion sensors. Anal. Chem. 2000, 72, 1127-1133. [CrossRef]

33. Kirsanov, D.; Panchuk, V.; Agafonova-Moroz, M.; Khaydukova, M.; Lumpov, A.; Semenov, V.; Legin, A. A sample-effective calibration design for multiple components. Analyst 2014, 139, 4303-4309. [CrossRef] 
34. Suzuki, H.; Naganawa, H.; Tachimori, S. Role of hydrophobic counteranions in the ion pair extraction of lanthanides(III) with an electrically neutral extractant. Phys. Chem. Chem. Phys. 2003, 5, 726-733. [CrossRef]

35. Lumetta, G.J.; Gelis, A.V.; Braley, J.C.; Carter, J.C.; Pittman, J.W.; Warner, M.G.; Vandegrift, G.F. The TRUSPEAK Concept: Combining CMPO and HDEHP for Separating Trivalent Lanthanides from the Transuranic Elements. Solvent Extr. Ion Exch. 2013, 31, 223-236. [CrossRef]

36. Alyapyshev, M.Y.; Babain, V.A.; Tkachenko, L.I.; Eliseev, I.I.; Didenko, A.V.; Petrov, M.L. Dependence of Extraction Properties of 2,6-Dicarboxypyridine Diamides on Extractant Structure. Solvent Extr. Ion Exch.e 2011, 29, 619-636. [CrossRef]

37. Faber, K.; Kowalski, B.R. Propagation of measurement errors for the validation of predictions obtained by principal component regression and partial least squares. J. Chemom. 1997, 11, 181-238. [CrossRef] 